\title{
Pregnancy-Associated Plasma Protein A and Proform Eosinophilic Major Basic Protein in the Detection of Different Types of Coronary Artery Disease
}

\author{
P. HÁJEK* ${ }^{1}$, M. MACEK $*^{2}$, M. HLADÍKOVÁ ${ }^{3}$, B. HOUBOVÁ ${ }^{2}$, D. ALAN ${ }^{1}$, V. DURDIL ${ }^{1}$, \\ J. FIEDLER ${ }^{1}$, M. MALÝ ${ }^{1}$, P. OŠŤÁDAL ${ }^{1}$, J. VESELKA $^{\mathbf{1}}$, A. KREBSOVÁ $^{\mathbf{4}}$ \\ * Petr Hajek, M.D. and Assoc. Prof. Milan Macek Sr., M.D., PhD. contributed equally to this work
}

${ }^{1}$ Department of Cardiology, ${ }^{2}$ Institute of Biology and Medical Genetics, ${ }^{3}$ Institute of Medical Informatics, Second Medical School and University Hospital of Charles University Prague, Czech Republic, ${ }^{4}$ Department of Internal Medicine / Cardiology, Virchow Klinikum, Humboldt University, Berlin, Germany

Received March 28, 2006

Accepted November 20, 2006

On-line available January 2, 2007

\begin{abstract}
Summary
Kryptor system was proven to be a rapid, standard method for pregnancy-associated plasma protein A and proform eosinophilic major basic protein (PAPP-A/proMBP) complex detection in coronary artery disease (CAD). No age and/or gender differences in 51 controls and 110 stable coronary artery disease (SCAD) patients were found. SCAD patients did not differ from controls and no difference in PAPP-A/proMBP levels with regards to the number of affected vessels was found. In 21 unstable angina pectoris (UAP), in 35 without and 66 with ST elevation acute myocardial infarctions (NSTEMI, STEMI respectively) patients PAPP-A/proMBP levels were increased $(P=0.004$ and $P<0.0005$, respectively). PAPP-A/proMBP levels did not correlate with cardiac troponin I (cTnI) in STEMI and NSTEMI patients. PAPP-A/ proMBP increase was more frequent than $C T n I(P=0.036)$ within the early phase of STEMI. In NSTEMI patients PAPP-A/proMBP positivity was present in $50 \%$ of $\mathrm{CTnI}$ negative cases. Receiver operating characteristic (ROC) analysis revealed the highest diagnostic accuracy of PAPP-A/proMBP (0.919) in STEMI CTnI positive cases. The highest specificity/sensitivity PAPP-A/proMBP levels for particular acute coronary syndrome (ACS) types were 10.65-14.75 mIU/l. Combination of PAPP-A/proMBP with cTnI increases their diagnostic efficacy within the early phase of ACS. Our results suggest that PAPP-A/proMBP complex is involved in processes preceding vulnerable plaque development in ACS.
\end{abstract}

\section{Key words}

Coronary artery disease $\bullet$ PAPP-A/proMBP • Cardiac troponin I • Atherosclerosis

\section{Corresponding author}

Petr Hájek, University Hospital Motol, Department of Cardiology, V Úvalu 84, Prague 5, 150 06, Czech Republic, Fax: +420 224 434 920, E-mail: petr.hajek@fnmotol.cz

\section{Introduction}

Pregnancy-associated plasma protein A (PAPP-A) belongs to the metzincin metalloproteinase superfamily. As an IGF-I-binding protein (IGFBP-4,5) metalloproteinase it cleaves inhibitory IGFBP-4,5 to amplify local insulin-like growth factor I (IGF-I) availability (Lawrence et al. 1999, Laursen et al. 2001). In pregnancy PAPP-A is linked as a heterotetrameric 2:2 complex to the proform of eosinophil major basic protein (proMBP) with a minor proportion of 2:1 linkage to proMBP or as an uncomplexed PAPP-A (Oxvig et al. 1993, Overgaard et al. 2000).

ProMBP is a heterogeneously glycosylated proteoglycane that is processed in maturing eosinophile granules to $14 \mathrm{kDA}$ eosinophilic major basic protein (MBP) (Overgaard et al. 1999). In pregnancy, angiotensinogen forms 2:2 complex of angiotensinogen and proMBP. The other 2:2:2 complex is between proMBP, angiotensinogen and complement C3dg (Oxvig et al. 1995). This complex increases during blood coagulation suggesting blood complement activation (Christiansen et al. 2000).

PAPP-A was detected in the serum as a potentially early indicator of acute coronary syndrome (ACS) (Bayes-Genis et al. 2001a,b). Increased levels of PAPP-A protein were observed in subjects at high cardiovascular risk with increased echogenicity of carotid 
plaques (Beaudeaux et al. 2003). The different evaluation of their impact in patients with acute myocardial infarction (AMI) (Qin et al. 2002, Dominguez-Rodriguez et al. 2005), in the prediction of ischemic cardiac events, need of revascularization (Lund et al. 2003, Laterza et al. 2004, Heeschen et al. 2005) and diagnostic relationship to elevated creatine kinase MB fraction (CK-MBmass) and cardiac troponin I (cTnI) in serial serum examinations (Khosravi et al. 2002) in the acute coronary syndrome substantiated further clinical studies.

The aim of this study was to validate a standard, rapid, commercially available, diagnostic system measuring simultaneously PAPP-A/proMBP complex with regards to its possible pathogenetic role in the development of coronary artery disease (CAD) (Chen et al. 2003, Che et al. 2002, Spencer 2003, Resch et al. 2004). Therefore, this study was focused on the ascertainment of PAPP-A/proMBP complex diagnostic efficacy within the earliest clinical phase of ACS in comparison to $\mathrm{cTnI}$ representing the currently most important ACS biomarker in cohort of cases with exactly clinically and angiographically determined different types of CAD.

\section{Methods}

The Internal Ethics Review Board of the University Hospital Prague-Motol approved this prospective study and all study subjects signed respective informed consent forms prior to coronary angiography. Patients with different types of CAD were sampled without any selection bias. Exclusion criteria included advanced kidney, liver, overt heart failure and history of major surgery or trauma within the previous month, pregnancy, known or suspected inflammatory and/or neoplastic diseases.

Prolonged chest pain with ST elevation and increased CK-MBmass, more than twice above its upper limit $(>9.2 \mu \mathrm{g} / \mathrm{l})$, and the cTnI level of more than $0.5 \mu \mathrm{g} / 1$ characterized STEMI patients. NSTEMI patients differed by ST segment depressions or $\mathrm{T}$ wave inversions. Patients with unstable angina pectoris (UAP) were defined by chest discomfort at rest with either ST segment depression of at least $0.1 \mathrm{mV}$ or $\mathrm{T}$ wave inversion in two or more contiguous electrocardiographic leads, normal CK-MB, cTnI levels and CAD confirmed by angiography. Patients with stable CAD had effortinduced chest pain and/or positive stress test and severe CAD without ischemic episodes during the week preceding respective angiography (Table 1). PAPP-A and proMBP complex (PAPP-A/proMBP) was examined in 122 ACS patients. They comprised 66 STEMI (mean age \pm SD was $62 \pm 10$ years), 35 NSTEMI ( $67 \pm 10$ years) and 21 UAP individuals (66 \pm 12 years). Obtained results were compared to 51 controls (59 \pm 9 years) with suspected CAD, but with normal coronary angiography or minimal vessel irregularities and 110 cases with stable coronary artery disease ( $64 \pm 9$ years).

Age, gender, height, weight, blood pressure levels, cardiovascular risk factors as hypertension, diabetes mellitus, smoking, family history of CAD, hyperlipidemia and cardiac medication were evaluated (Table 1).

Blood samples were obtained during angiography and/or at routine admission examinations. The mean time \pm SD from the last ischemic episode with chest pain to blood sampling in STEMI was $4 \pm 3.3 \mathrm{~h}$ within $1-12 \mathrm{~h}$, in NSTEMI $9.1 \pm 2.1 \mathrm{~h}$ within $1-24 \mathrm{~h}$ and in UAP $15.5 \pm 9.5 \mathrm{~h}$ within $3-24 \mathrm{~h}$.

Frozen sera $\left(-20^{\circ} \mathrm{C}\right)$, prepared within $1-2 \mathrm{~h}$ after the blood sampling, were used for examination of PAPP-A/proMBP by Kryptor ${ }^{\mathrm{TM}}$ system (BrahmsGermany), based on the time-resolved amplified cryptate emission, validated within the first trimester biochemical screening (Spencer 2003). cTnI was analyzed by the Immulite Turbo Troponin I kit and immulite analyzer (DPC USA) with the lowest measurable levels of $0.5 \mu \mathrm{g} / 1$.

Angiography was performed in all patients to determine the extent of coronary atherosclerosis before heart surgery or because of CAD symptoms. Severe CAD was defined by the presence of one or more stenoses with at least $70 \%$ diameter reduction on any major coronary artery.

Continuous variables were expressed as mean \pm $\mathrm{SD}$, discrete variables as counts and percentages. Nonparametric tests were used due to non-Gaussian distribution of PAPP-A/proMBP. These were compared among the groups using the Kruskal-Wallis test. In case of rejecting the hypothesis of all group equality, couples of groups were compared by the Mann-Whitney test. Bonferroni correction of statistical significance was applied in the case of multiple comparisons. Spearman's correlation coefficient was used to evaluate relationship of PAPP-A/proMBP to age and to cTnI. Chi-square test or Fisher's exact test were used to compare occurrence of the risk factors among the examined cohorts. McNemar test was used to compare frequency of increased levels of 
Table 1. Clinical characteristics of studied patients

Clinical characteristics

Characterization of the sample under investigation

\begin{tabular}{|c|c|c|c|c|c|c|}
\hline & & $\begin{array}{l}\text { Control } \\
(\mathbf{n}=51)\end{array}$ & $\begin{array}{l}\text { SCAD } \\
(\mathrm{n}=110)\end{array}$ & $\begin{array}{l}\text { UAP } \\
(n=21)\end{array}$ & $\begin{array}{l}\text { NSTEMI } \\
(\mathrm{n}=\mathbf{3 5})\end{array}$ & $\begin{array}{l}\text { STEMI } \\
(\mathrm{n}=66)\end{array}$ \\
\hline \multirow{2}{*}{$\begin{array}{l}\text { Mean age } \\
\text { (years) (range }\end{array}$} & Male & $55(38-68)$ & $63(42-87)$ & $65(42-82)$ & $65(45-82)$ & $59(41-82)$ \\
\hline & Female & $61(44-76)$ & $65(48-77)$ & $68(46-82)$ & $69(49-86)$ & $70(48-83)$ \\
\hline \multirow{2}{*}{$\begin{array}{l}\text { Sex } \\
\text { no. }(\%)\end{array}$} & Male & $17(33.3)$ & $81(73.6)$ & $13(61.9)$ & $24(68.6)$ & $51(77.3)$ \\
\hline & Female & $34(66.7)$ & $29(26.4)$ & $8(39.1)$ & $11(31.4)$ & $15(22.7)$ \\
\hline \multirow{4}{*}{$\begin{array}{l}\text { Risk factors } \\
\text { no. (\%) }\end{array}$} & Arterial hypertension & $25(49)$ & $69(62.7)$ & $17(81) * t$ & $23(65.7)$ & $24(38.1) \dagger$ \\
\hline & Smoking & $15(29.4)$ & $28(25.5)$ & $2(9.5) \div$ & $14(40)$ & $35(54.7)^{*}$ \\
\hline & Hyperlipoproteinemia & $23(45.1)$ & $72(65.5) * \$$ & $7(33.3)$ & $10(28.6)^{\#}$ & $12(18.8)^{*}$ \\
\hline & Diabetes mellitus & $9(17.6)$ & $35(31.8)$ & $8(38.1)$ & $14(40)^{*}$ & $8(12.5) \dagger$ \\
\hline \multirow{6}{*}{$\begin{array}{l}\text { Therapy } \\
\text { no. (\%) }\end{array}$} & Aspirin & $34(68)$ & $92(84.4)^{* \S}$ & $13(65) \sharp$ & $15(46.9) \dagger^{\#}$ & $14(21.5)^{*}$ \\
\hline & Beta-blockers & $24(48)$ & $81(74.3)^{* \S}$ & $9(45) \ddagger$ & $14(43.8) \dagger^{\#}$ & $12(18.5)^{*}$ \\
\hline & $A C E$ inhibitors & $22(44)$ & $59(54.1)^{\S}$ & $8(40) !$ & $8(25)^{\#}$ & $10(15.4)^{*}$ \\
\hline & Nitrates & $22(44)$ & $66(60.6)^{* \S}$ & $9(45) !$ & $9(28.1)^{\#}$ & $9(13.8)^{*}$ \\
\hline & Statins & $10(20)$ & $49(45)^{* \S}$ & $5(25)$ & $3(9.4)^{\#}$ & $6(9.2)$ \\
\hline & Calcium-channel blockers & $12(24)$ & $18(16.5)$ & $3(15)$ & $4(12.5)$ & $6(9.2)$ \\
\hline \multirow{3}{*}{$\begin{array}{l}\text { Angiographic } \\
\text { findings no.(\%) }\end{array}$} & One vessel disease & 0 & $40(36.7)$ & $6(28.6)$ & $8(28.6)$ & $26(40.6)$ \\
\hline & Two vessel disease & 0 & $25(22.9)$ & $5(23.8)$ & $4(14.3)$ & $21(32.6)$ \\
\hline & Three vessel disease & 0 & $44(40.4)$ & $10(47.6)$ & $16(57.1)$ & $17(26.6)$ \\
\hline
\end{tabular}

$* \mathrm{P}<0.05$ - comparison to controls; $+\mathrm{P}<0.05$ - comparison of NSTEMI versus STEMI; $\neq \mathrm{P}<0.05$ - comparison of UAP versus STEMI; ${ }^{\#} \mathrm{P}<0.05$ - comparison of SCAD versus NSTEMI; ${ }^{\S} \mathrm{P}<0.05$ - comparison of SCAD versus STEMI; SCAD - stable coronary artery disease, UAP - unstable angina pectoris, STEMI - acute myocardial infarction with ST elevation, NSTEMI - acute myocardial infarction without ST elevation.

PAPP-A/proMBP and cTnI.

Receiver operating characteristic (ROC) curves (Swets 1988) were applied for the evaluation of the diagnostic accuracy of PAPP-A/proMBP in ACS patients by the size of the area under ROC curve (AUC). AUC $>0.9$ indicates the highest diagnostic accuracy, 0.65-0.9 confident diagnostic utility, 0.5-0.65 low diagnostic accuracy. Areas under ROC curve for different tests were compared according to the overlap of their confidence intervals and according U-test. ROC analysis provided also ascertainment of the highest specificity and sensitivity (HSS) of PAPP-A/proMBP. The SPSS software for Windows (Release 10.0.7) was used. Percentiles were qualified using the weighted average method.

\section{Results}

Clinical characteristics, type of medication, mutual comparison of patients and controls (Table 1) reflect general health status of this age group. Chi square test revealed no differences in the number of affected vessels among $\mathrm{CAD}$ patients when all types were compared together. 
Table 2. Levels of PAPP-A/proMBP (mIU/l) in different types of CAD

\begin{tabular}{llllll}
\hline & $\begin{array}{l}\text { Controls } \\
(\mathbf{n}=\mathbf{5 1})\end{array}$ & $\begin{array}{l}\text { SCAD } \\
(\mathbf{n}=\mathbf{1 1 0})\end{array}$ & $\begin{array}{l}\text { UAP } \\
(\mathbf{n}=\mathbf{2 1})\end{array}$ & $\begin{array}{l}\text { NSTEMI } \\
(\mathbf{n}=\mathbf{3 5})\end{array}$ & $\begin{array}{l}\text { STEMI } \\
(\mathbf{n}=\mathbf{6 6})\end{array}$ \\
\hline $\begin{array}{l}\text { Mean } \pm S D \\
2 S D\end{array}$ & $7.28 \pm 3.57$ & $7.91 \pm 3.61$ & $19.73 \pm 19.78$ & $21.13 \pm 24.71$ & $30.3 \pm 30.11$ \\
Median & 7.14 & & & & \\
Range & 7.5 & 8.1 & 11.4 & 14.3 & 17.75 \\
2 Medians & $0-14.2$ & $0-16.4$ & $0-68.3$ & $0-123$ & $0-146.8$ \\
P1 & 15 & & & & \\
P2 & & 0.14 & 0.004 & $<0.0005$ & $<0.0005$ \\
P3 & & $0.011^{*}$ & $<0.0005$ & $<0.0005$ \\
P4 & & & 0.5 & $0.045^{*}$ \\
\hline
\end{tabular}

P1 - comparison of SCAD, UAP, NSTEMI, STEMI vs. controls; P2 - comparison of UAP, NSTEMI, STEMI vs. SCAD; P3 - comparison of NSTEMI, STEMI vs. UAP; P4 - comparison of STEMI vs. NSTEMI; PAPP-A/proMBP was compared among the groups using the KruskalWallis test. In case of rejecting the hypothesis of all groups equality, couples of groups were compared by the Mann-Whitney test. * according to Bonferroni correction labeled $\mathrm{p}$ values did not document statistical significance despite $\mathrm{P} \leq 0.05$, because significant values corresponded to $\mathrm{a}<0.005$ for ten groups compared. SCAD - stable coronary artery disease; UAP - unstable angina pectoris, STEMI - acute myocardial infarction patients with ST elevation; NSTEMI - acute myocardial infarction patients without ST elevation.

Table 3. Percentile values of PAPP-A/proMBP (mIU/l) in controls and patients with different types of CAD - sensitivity of PAPP-A/proMBP for diagnosis of particular ACS types.

\begin{tabular}{lllllll}
\hline Studied group & $\mathbf{7 5}^{\text {th }}$ percentile & sensitivity & $\mathbf{9 0}^{\text {th }}$ percentile & sensitivity & $\mathbf{9 5}^{\text {th }}$ percentile & sensitivity \\
\hline Controls & 9.6 & & 12.32 & & 13.84 & \\
SCAD & 10 & & 12.3 & & 13.6 & \\
UAP & 27.4 & 0.57 & 60.38 & 0.43 & 67.86 & 0.38 \\
NSTEMI & 20.75 & 0.71 & 45.15 & 0.62 & 102.37 & 0.59 \\
STEMI & 45.05 & 0.77 & 61.95 & 0.72 & 102.4 & 0.66 \\
\hline
\end{tabular}

SCAD - stable coronary artery disease, UAP - unstable angina pectoris, NSTEMI - acute myocardial infarction without ST elevation, STEMI - acute myocardial infarction with ST elevation.

The PAPP-A/proMBP values in controls are shown in Table 2. No gender $(\mathrm{P}=0.11)$ and age $(\mathrm{P}=0.5)$ differences were revealed. Mean levels were $7.28 \pm 3.57$ $\mathrm{mIU} / \mathrm{l}$ in agreement with medians. The lowest measurable value was $3.42 \mathrm{mIU} / \mathrm{l}$. The $75-95^{\text {th }}$ percentile PAPPA/proMBP levels are in the Table 3. Non-measurable levels were found in 5 of 51 individuals (9.8\%).

A single control patient (1/51) had higher level (38.5 mIU/l) than mean $\pm 2 \mathrm{SD} / 2$ medians with elevated hs-CRP $(5 \mathrm{mg} / \mathrm{l})$. This female was under long-term oncogynecology surveillance after hysterectomy. In 9 out of 51 control patients the PAPP-A/proMBP levels were within the range 10-14.2 mIU/l. In 5 of them nephrosclerosis, recovery after bronchopneumonia and gastrointestinal bleeding, chronic duodenal ulcer, ulcerative colitis and chronic obstructive pulmonary disease were detected.
Mean levels of PAPP-A/proMBP in stable CAD $(7.91 \pm 3.61 \mathrm{mIU} / \mathrm{l})$ were not significantly different from controls $(\mathrm{P}=0.14)$ (Table 2). No gender $(\mathrm{P}=0.35)$ and age $(\mathrm{P}=0.98)$ differences were revealed within range of $42-87$ years. Males had higher levels than females $(8.19 \pm 3.42 \mathrm{mIU} / 1$ vs. $6.96 \pm 3.76 \mathrm{mIU} / 1, \mathrm{P}=0.034)$, only when controls and SCAD patients levels were pooled. The number of individuals with non-measurable levels was $11 / 110(10.0 \%)$. No differences in PAPP-A/proMBP levels between patients with one $(7.91 \pm 3.87 \mathrm{mIU} / \mathrm{l})$ and two or three affected vessels $(7.90 \pm 3.52 \mathrm{mIU} / \mathrm{l})$ were disclosed.

Highly increased levels of PAPP-A/proMBP in ACS (Table 2) were detected in UAP, NSTEMI and STEMI cases compared to controls. NSTEMI and STEMI patients differed highly significantly from the SCAD cohort. No differences were disclosed between NSTEMI, STEMI and UAP and between NSTEMI and STEMI 
Table 4. Area under receiver operating characteristic (ROC) curve of PAPP-A/proMBP in ACS.

\begin{tabular}{|c|c|c|c|c|c|c|}
\hline \multirow[t]{2}{*}{ Types of ACS } & & \multirow[t]{2}{*}{ Area } & \multirow[t]{2}{*}{ Std. Error } & \multicolumn{2}{|c|}{$\begin{array}{c}\text { Asymptotic } 95 \% \text { confidence } \\
\text { interval }\end{array}$} & \multirow{2}{*}{$\begin{array}{l}\text { HSS } \\
(\mathrm{mIU} / \mathrm{l})\end{array}$} \\
\hline & & & & Lower band & Upper band & \\
\hline $\operatorname{STEMI}(c \operatorname{Tn} I+, 0)$ & $v s(C)$ & 0.865 & 0.034 & 0.798 & 0.932 & 12.05 \\
\hline $\operatorname{STEMI}(c \operatorname{Tn} I+, 0)$ & $v s(C+S C A D)$ & 0.849 & 0.034 & 0.782 & 0.816 & 12.05 \\
\hline $\operatorname{STEMI}(c T n I+)$ & $v s(C)$ & 0.919 & 0.036 & 0.849 & 0.989 & 12.30 \\
\hline STEMI (cTnI 0) & vs $C$ & 0.812 & 0.052 & 0.711 & 0.914 & 14.75 \\
\hline $\operatorname{NSTEMI}\left(c \operatorname{cTn} I^{+}, 0\right)$ & $v s(C)$ & 0.803 & 0.054 & 0.696 & 0.909 & 14.25 \\
\hline $\operatorname{NSTEMI}(c \operatorname{Tn} I+)$ & $v s(C)$ & 0.828 & 0.063 & 0.704 & 0.952 & 12.35 \\
\hline NSTEMI (cTnI 0) & $v s(C)$ & 0.755 & 0.092 & 0.574 & 0.936 & 14.25 \\
\hline STEMI+NSTEMI $(c T n I+, 0)$ & $v s(C)$ & 0.843 & 0.031 & 0.782 & 0.805 & 14.25 \\
\hline STEMI+NSTEMI $(c \operatorname{Tn} I+, 0)$ & vs $U A P$ & 0.613 & 0.071 & 0.474 & 0.752 & 12.75 \\
\hline$U A P$ & $v s(C)$ & 0.718 & 0.072 & 0.577 & 0.860 & 10.65 \\
\hline$U A P+S T E M I+N S T E M I$ & $v s(C)$ & 0.821 & 0.031 & 0.760 & 0.883 & 14.25 \\
\hline $\operatorname{STEMI}(c \operatorname{TnI}+, 0)$ & vs $(S C A D)$ & 0.841 & 0.036 & 0.771 & 0.912 & 12.00 \\
\hline $\operatorname{NSTEMI}(c \operatorname{Tn} I+, 0)$ & vs (SCAD) & 0.775 & 0.056 & 0.664 & 0.885 & 13.5 \\
\hline$U A P$ & $v s(S C A D)$ & 0.675 & 0.076 & 0.525 & 0.825 & 11.15 \\
\hline
\end{tabular}

HSS - best sensitivity/specificity PAPP-A/proMBP levels; (cTnI+/0) - troponin positivity $(>0.5 \mu \mathrm{g} / \mathrm{l}) /$ negativity $(<0.5 \mu \mathrm{g} / \mathrm{l})$ in AMI patients; $(\mathrm{cTnI}+, 0)$ - troponin positivity $(>0.5 \mu \mathrm{g} / \mathrm{l})$ and negativity $(<0.5 \mu \mathrm{g} / \mathrm{l})$ alltogether in AMI patients; (C) - control PAPP-A/proMBP levels; (C + SCAD) - pooled control and SCAD PAPP-A/proMBP levels; (SCAD) - SCAD PAPP-A/proMBP levels. Areas under ROC curves were compared by the U-test in STEMI $(\mathrm{cTnI}+, 0)$ vs. $\mathrm{C}$ to UAP vs. $\mathrm{C}$, NSTEMI $(\mathrm{cTnI}+, 0)$ vs. C to UAP vs. $\mathrm{C}, \mathrm{STEMI}(\mathrm{cTnI}+, 0)$ vs. $\mathrm{C}$ to NSTEMI $(\mathrm{cTnI}+, 0)$ vs. C, STEMI+NSTEMI) vs. UAP to UAP $\times$ C and STEMI (cTnI+) vs. C to UAP vs. C; U-test disclosed statistical significance for the comparison of STEMI (CTnI+) vs. C to UAP vs. C only (U-test $=2.49, P=0.0127$ ). SCAD - stable coronary artery disease, UAP - unstable angina pectoris; NSTEMI - acute myocardial infarction patients without ST elevation, STEMI - acute myocardial infarction patients with ST elevation.

patients. The number of individuals with non-measurable levels was $1 / 21(4.8 \%)$ in UAP, $2 / 35(5.7 \%)$ in NSTEMI and $1 / 66(1.51 \%)$ in STEMI patients. Percentile values with corresponding diagnostic sensitivity are listed in Table 3.

PAPP-A/proMBP ROC curves analysis in different types of ACS are shown in Table 4 and Fig. 1. ROC curves demonstrate that PAPP-A/proMBP levels provided a confident diagnostic utility for the discrimination of all ACS types from control levels as well as from controls combined with SCAD patients. The best specificity/sensitivity (HSS) PAPP-A/proMBP levels correspond to the range 10.65-14.75 mIU/1 (comparison to control levels) for particular ACS types. The highest diagnostic accuracy (AUC $=0.919)$ was found in cTnI positive $(\mathrm{cTnI}+)$ STEMI patients (Table 4). The lowest AUC was in discrimination of AMI from UAP individuals (AUC $=0.613$ ).

A comparison of AUC in different ACS patient groups indicates that significant difference, evaluated by the U-test, was detected only between troponin-positive
STEMI (cTnI+ vs. controls) and UAP patients (UAP vs. controls $)(\mathrm{P}=0.01 \mathrm{U}$-test $=2.49)$. Tendencies towards significant differences were found between STEMI troponin-positive $(\mathrm{cTnI}+)$ and STEMI troponin-negative (cTnI 0) patients $(\mathrm{P}=0.09$ U-test $=1.69)$ and STEMI and NSTEMI troponin-positive patients $(\mathrm{P}=0.07$ U-test $=$ 1.79). The same was true for the comparison of all STEMI $(\mathrm{cTnI}+, 0)$ and UAP patients $(\mathrm{P}=0.06$ U-test $=$ 1.84). No statistical significant differences were disclosed between other different ACS groups.

The comparison of PAPP-A/proMBP and cTnI in AMI patients indicated that in STEMI patients the levels of cTnI were $6.6 \pm 18.2 \mu \mathrm{g} / \mathrm{l}$ at the time of the blood sampling for PAPP-A/proMBP and maximal cTnI levels was $146 \pm 163 \mu \mathrm{g} / \mathrm{l}$. In NSTEMI patients the first levels of cTnI were $5.8 \pm 8.9 \mu \mathrm{g} / \mathrm{l}$ and maximal cTnI levels were $27.9 \pm 35.4 \mu \mathrm{g} / \mathrm{l}$.

In STEMI patients no correlations between PAPP-A/proMBP and cTnI levels were revealed (Spearman's rho $=0.038, \mathrm{P}=0.768$ ), as in both STEMI and NSTEMI patients (Spearman's rho $=0.07, \mathrm{P}=0.47$ for 
Table 5. Comparison of c-Troponin I and PAPP-A/proMBP in STEMI patients in the range of $>75$ to $>95$ percentiles.

\begin{tabular}{|c|c|c|c|c|c|c|}
\hline \multirow[t]{2}{*}{ c-Troponin I } & \multicolumn{6}{|c|}{$\begin{array}{l}\text { PAPP-A/proMBP }(\mathrm{mIU} / \mathrm{l}) \\
>90 \text { percentile }(>12.3 \mathrm{mIU} / \mathrm{l})\end{array}$} \\
\hline & $<75$ percentile & $>75$ percentile & $<90$ percentile & $>90$ percentile & $<95$ percentile & $>95$ percentile \\
\hline $\begin{array}{l}\text { Negativity } \\
(<0.5 \mu g / l)\end{array}$ & $\begin{array}{c}11 \\
(17.46 \%)\end{array}$ & $\begin{array}{c}23 \\
(36.51 \%)\end{array}$ & $\begin{array}{c}14 \\
(22.22 \%)\end{array}$ & $\begin{array}{c}20 \\
(31.75 \%)\end{array}$ & $\begin{array}{c}14 \\
(22.22 \%)\end{array}$ & $\begin{array}{c}20 \\
(31.75 \%)\end{array}$ \\
\hline $\begin{array}{l}\text { Positivity } \\
(>0.5 \mu \mathrm{g} / \mathrm{l})\end{array}$ & $\begin{array}{c}4 \\
(6.35 \%)\end{array}$ & $\begin{array}{c}25 \\
(39.68 \%)\end{array}$ & $\begin{array}{c}4 \\
(6.35 \%)\end{array}$ & $\begin{array}{c}25 \\
(39.68 \%)\end{array}$ & $\begin{array}{c}8 \\
(12.70 \%)\end{array}$ & $\begin{array}{c}21 \\
(33.33 \%)\end{array}$ \\
\hline$P$ & & & 0 & & & \\
\hline
\end{tabular}

$\%$ - from total number of 63 patients examined, P - statistical significance (evaluated by McNemar test) between the number of either PAPP-A/proMBP or c-Troponin I only positive patients. It was ascertained in the group of c-Troponin I negative patients $(<0.5 \mu \mathrm{g} / \mathrm{l})$ and positive patients $(>0.5 \mu \mathrm{g} / \mathrm{l})$ and PAPP-A/proMBP levels. PAPP-A/proMBP positivity in the range of $>75$ percentiles corresponds to the levels $>9.6 \mathrm{mIU} / \mathrm{l}$, in the range $>90$ percentiles corresponds to $>12.3 \mathrm{mIU} / \mathrm{l}$ and in the range $>95$ percentiles corresponds to $>13.84$ $\mathrm{mIU} / \mathrm{l}$.

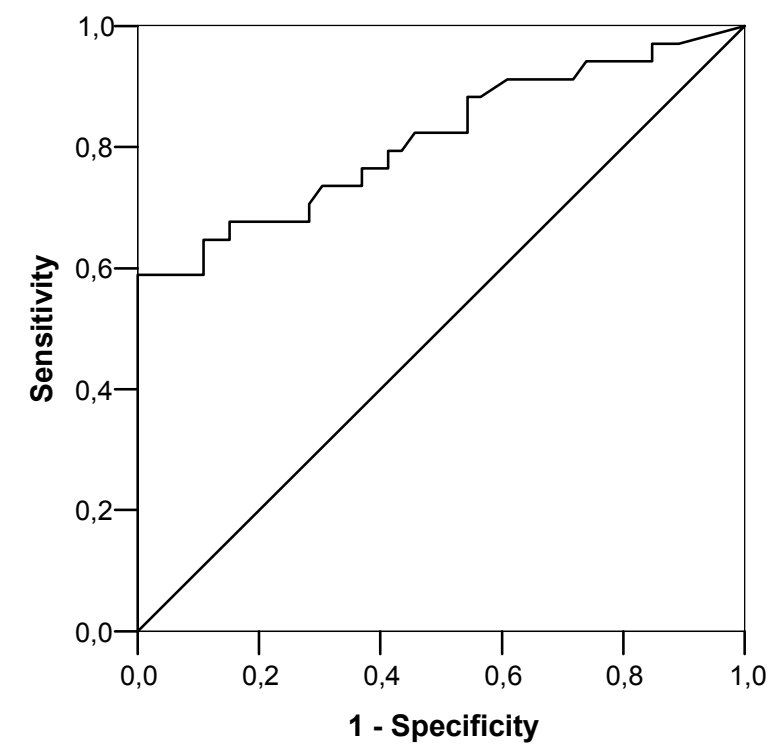

Fig. 1. ROC curve of PAPP-A/proMBP in STEMI cTnI negative patients. This figure documents diagnostic impact of PAPP-A/ proMBP in the first hours after the onset of chest pain; in these STEMI patients CTnI increase was not revealed yet. STEMI acute myocardial infarction patients with ST elevation, AUC area under ROC curve, cTnI - Troponin I.

cTnI, Spearman's rho $=0.11, \mathrm{P}=0.26$ for $\mathrm{cTnI}$ max).

The analysis of cTnI and PAPP-A/proMBP levels in STEMI patients (Table 5) in the range of $>75$ to $>95$ percentiles revealed that in the group with levels $>75$ percentiles there is highly significant prevalence (McNemar test, $\mathrm{P}=0.0003$ ) of PAPP-A/proMBP only positive patients compared to $\mathrm{cTnI}$ only positive cases $(>0.5 \mu \mathrm{g} / \mathrm{l})$. Such a significant difference also remains in patients with levels $>90$ and $>95$ percentiles (McNemar test, $\mathrm{P}=0.002$ and 0.036 , respectively). PAPP-A/proMBP increased levels were disclosed earlier in 20 out of 34 (58.8 \%) STEMI cTnI-negative patients (Table 5) within the range of $>95$ percentiles.

In NSTEMI patients no differences in the prevalence of $\mathrm{cTnI}$ and PAPP-A/proMBP positivities within the range of $>75,>90$ and $>95$ percentiles (McNemar test, $\mathrm{P}=0.8-1.0$, respectively) were observed. Nevertheless, PAPP-A/proMBP positivity with levels $>75$ percentiles was detected in 7 out of $12(58.3 \%)$, in $>90$ and $>95$ percentiles in 6 out of $12(50 \%)$ cTnInegative patients.

\section{Discussion}

To our best knowledge this is the first study where PAPP-A and proMBP proteins were examined simultaneously in randomly sampled controls and all types of CAD patients utilizing commercial automatic Kryptor detection system, which was verified in prenatal biochemical screening (Spencer et al. 2003). Analysis is completed within $30 \mathrm{~min}$ and thus it is feasible for clinical practice compared to the use of more demanding techniques (Bayes-Genis et al. 2001a, DominguezRodriguez et al. 2005, Lund et al. 2003, Laterza et al. 2004, Heeschen et al. 2005). Low frequency of nonmeasurable levels, decreasing with clinical severity of CAD types, did not influence statistical significance and clinical impact of this study, since medians, non- 
parametric tests and other appropriate tests were used for comparisons.

Recent results of Qin et al. (2005) indicate, that circulating ACS-related PAPP-A is non-complexed with proMBP and/or both types of complexed and uncomplexed PAPP-A proteins are present in ACS patients (Qin et al. 2006). This might explain nonmeasurable/normal and high variability of PAPPA/proMBP levels in some our ACS patients (Table 2). Furthermore, some fatal AMI cases (Farb et al. 1996) are caused by thrombosis on a deendotelized, but otherwise intact plaque.

Our results prove that the Kryptor system provides relevant detection of serum PAPP-A complexed and uncomplexed with proMBP within the great majority of ACS patients. Our unpublished results with PerkinElmer ELISA kits applied in prenatal screening provided the same diagnostic utility in these CAD patients. Our data indicate that normal serum PAPP-A/proMBP levels decrease the risk of an unstable plaque presence.

Our control levels of PAPP-A/proMBP complex (Tables 2 and 3) are slightly higher than PAPP-A levels reported by Qin et al. (2002) - $5.68 \mathrm{mIU} / 1$ or Cosin-Sales et al. (2004) - 4.62 vs. $7.28 \mathrm{mIU} / 1$. PAPP-A/proMBP levels were increased in the range of levels of different ACS type in 10 out of 51 control patients. In six of them it might be explained by reparative processes accompanying also other pathologic affections including neoplasia with known PAPP-A/proMBP involvement in healing (Chen et al. 2003) and angiogenesis (Jadlowiec et al. 2005). That has to be taken into the account in diagnostic evaluation of increased PAPP-A/proMBP levels in different types of CAD.

Different even contradictory observations concerning the clinical implementation of PAPP-A in ACS (Dominguez-Rodriguez et al. 2005, Laterza et al. 2004) might also be due to the use of different detection methods. Standard/feasible methods to ascertain the difference and ratios between different types of PAPP-A in CAD (Qin et al. 2005, 2006) are necessary to be developed and validated in subsequent studies.

So far only Cosin-Sales et al. (2004) in stable CAD studied ratio of PAPP-A to proMBP. Our results indicate that simultaneous PAPP-A/proMBP detection might improve PAPP-A diagnostic and possible prognostic validity in all CAD types. It is also supported by the fact that proMBP partially inhibits proteolytic PAPP-A activity (Overgaard et al. 1999, 2000) and thus its presumed role in the atherosclerotic process (Qin et al.
2005, Bayes-Genis et al. 2000, Aso et al. 2004, Apple et al. 2005), in inflammation and plaque disruption risk (Che et al. 2002, Resch et al. 2004). The diagnostic/prognostic value of this protein complex corresponds to the observation that its formation is also enhanced by altered redox potentials under pathological conditions (Glerup et al. 2005) and by angiotensinogen and complement $\mathrm{C} 3 \mathrm{dg}$ binding to the proMBP (Oxvig et al. 1995, Christiansen et al. 2000). ProMBP is also a carrier of active molecules for tissue remodeling and differentiation and is believed to neutralize cytotoxicity of MBP (Bonno et al. 1994), what was confirmed in eosinophilic endomyocarditis and in myocardial infarction (Tai et al. 1987, Rauch et al. 1997). PAPP-A decreases the risk of thromboembolism due to the inhibition of proMBP maturation to MBP. MBP promotes thrombosis by binding to the anionic endothelial protein thrombomodulin and impairing its anticoagulant activities (Slungaard et al. 1993).

In agreement with Bayes-Genis et al. (2001a,b), we observed that PAPP-A/proMBP values were not dependent on sex and age in controls and did not differ from controls in SCAD cases. Cosin-Sales et al. (2004, 2005) described increased PAPP-A levels correlating with age, male gender, hypertension, CAD extent, and complexity of coronary stenoses. We confirmed correlation with male gender only in pooled controls and SCAD PAPP-A/proMBP despite the fact that our PAPPA/proMBP levels were similar (7.3 \pm 3.6 vs. $5.5 \pm 1.6$ $\mathrm{mIU} / \mathrm{l})$. This observation could be explained by different detection methods, simultaneous measurements of PAPP$A$ and proMBP and/or lower number of our patients with established diagnostic limits of angiography.

The increased PAPP-A/proMBP levels in ACS patients with highest diagnostic validity in STEMI cTnI positive patients (Tables 2 and 4) suggest an association with the degree of coronary vessels alteration. It corresponds to increased PAPP-A levels in unstable plaques (Bayes-Genis et al. 2001a,b), including experimental restenosis by inflammatory cytokines, to its proatherogenic role (Lawrence et al. 1999) and promotion of the instability of the atherosclerotic plaque (Che et al. 2002).

PAPP-A/proMBP positivity in ACS patients corresponds to the cut-off levels higher than the 75th percentile (Tables 2 and 3). The highest sensitivity and specificity PAPP-A/proMBP values ascertained by ROC analysis (10.65-14.75 mIU/l) in different ACS types (Table 4) correspond also to $12.6 \mathrm{mIU} / 1$ of PAPP-A for 
maximized predictive value in ACS patients (Heeschen et al. 2005).

We revealed that in STEMI patients increased PAPP-A/proMBP levels are more frequent and an earlier biomarker than $\mathrm{cTnI}$. This evidence suggests involvement of PAPP-A/proMBP complex in the preceding processes of plaque formation, instability development including proliferative changes of coronary vessels. Furthermore, this is supported by the notion that increased PAPP-A may be a marker of atherosclerotic burden in asymptomatic patients with hypercholesterolemia (Štulc et al. 2003), of intimal hyperplasia only in hypercholesterolemic type II diabetics with carotid atherosclerosis (Aso et al. 2004) and of increased cardiovascular risk in hemodialyzed patients (Kalousová et al. 2004). These clinical data agree to experimental observations that PAPP-A is involved in matrix mineralization and angiogenesis (Jadlowiec et al. 2005). No correlations between PAPP-A/proMBP and cTnI levels in AMI patients also suggest their different role in AMI pathogenesis and its development.

Despite the fact, that PAPP-A/proMBP increased levels ( $>95$ percentiles) were in $50 \%$ of cTnInegative NSTEMI patients, the absence of its significant increased prevalence compared to cTnI, can be explained because of longer time between onset of chest pain and first blood sampling for simultaneous PAPP-A/proMBP and cTnI examinations. Nevertheless, simultaneous assessment of PAPP-A and cTnI increased diagnostic sensitivity in NSTEMI patients similarly as in early phase STEMI to $82 \%$ compared to the sensitivity of cTnI only (corresponding to $65 \%$ in NSTEMI and $46 \%$ in STEMI patients).

ROC analysis revealed that simultaneous assessment of PAPP-A/proMBP combined with $\mathrm{cTnI}$ (Tables 4 and 5, Fig. 1) will increase the diagnostic sensitivity/specificity of these biomarkers in the early phase of ACS development especially in the first hours after the onset of chest pain characterized by cTnI negativity (Fig. 1). Further studies focused on dynamic changes of PAPP-A/proMBP might contribute to the better understanding of ACS pathogenesis and diagnosis, therapeutic success and early prevention of adverse complications.

\section{Acknowledgements}

Supported by grant from the Ministry of Health of Czech Republic 00064203. Critical review of Prof. M. Macek Jr, M.D., DSc. and secretarial assistance of P. Roubic are highly appreciated.

\section{References}

APPLE FS, WU AHB, MAIR J, RAVKILDE J, PANTEGHINI M, TATE J, PAGANI F, CHRISTENSON RH, MOCKEL M, DANNE O, JAFFE S, on behalf of the Committee of Standardization of Markers of Cardiac Damage of the IFCC: Future biomarkers for detection of ischemia and risk stratification in acute coronary syndrome. Clin Chem 51: 810-824, 2005.

ASO Y, OKUMURA K, WAKABAYASHI S, TAKEBAYASHI K, TAKI S, INUKAI T: Elevated pregnancyassociated plasma protein-A in sera from type 2 diabetic patients with hypercholesterolemia: associations with carotid atherosclerosis and toe-brachial index. J Clin Endocrinol Metab 89: 5713-5717, 2004.

BAYES-GENIS A, CONOVER CA, SCHWARTZ RS: The insulin-like growth factor axis. A review of atherosclerosis and restenosis. Circ Res 86: 125-130, 2000.

BAYES-GENIS A, CONOVER CA, OVERGAARD MT, BAILEY KR, CHRISTIANSEN M, HOLMES DR Jr, VIRMANI R, OXVIG C, SCHWARTZ RS: Pregnancy-associated plasma protein A as a marker of acute coronary syndromes. $N$ Engl J Med 345: 1022-1029, 2001 a.

BAYES-GENIS A, SCHWARTZ RS, LEWIS DA, OVERGAARD MT, CHRISTIANSEN M, OXVIG C, ASHAI K, HOLMES DR JR, CONOVER CA: Insulin-like growth factor binding protein-4 protease produced by smooth muscle cells increases in the coronary artery after angioplasty. Arterioscler Thromb Vasc Biol 21: 335-341, 2001b.

BEAUDEUX JL, BURC L, IMBERT-BISMUT F, GIRAL P, BERNARD M, BRUCKERT E, CHAPMAN MJ: Serum plasma pregnancy-associated protein A: a potential marker of echogenic carotid atherosclerotic plaques in asymptomatic hyperlipidemic subjects at high cardiovascular risk. Arterioscler Thromb Vasc Biol 23: e7-e10, 2003. 
BONNO M, OXVIG C, KEPHART GM, WAGNER JM, KRISTENSEN T, SOTTRUP-JENSEN L, GLEICH GJ: Localization of pregnancy-associated plasma protein-A and colocalization of pregnancy-associated plasma protein-A messenger ribonucleic acid and eosinophil granule major basic protein messenger ribonucleic acid in placenta. Lab Invest 71: 560-566, 1994.

CHE W, LERNER-MARMAROSH N, HUANG Q, OSAWA M, OHTA S, YOSHIZUMI M, GLASSMAN M, LEE JD, YAN C, BERK BC, ABE J: Insulin-like growth factor-1 enhances inflammatory responses in endothelial cells: role of Gab1 and MEKK3 in TNF-alpha-induced c-Jun and NF-kappaB activation and adhesion molecule expression. Circ Res 90: 1222-1230, 2002.

CHEN BK, LEIFERMAN KM, PITTELKOW MR., OVERGAARD MT, OXVIG C, CONOVER CA: Localization and regulation of pregnancy-associated plasma protein A expression in healing human skin. $J$ Clin Endocrinol Metab 88: 4465-4471, 2003.

CHRISTIANSEN M, JALIASHVILI I, OVERGAARD MT, ENSINGER C, OBRIST P, OXVIG C: Quantification and characterization of pregnancy-associated complexes of angiotensinogen and the proform of eosinophil major basic protein in serum and amniotic fluid. Clin Chem 46: 1099-1105, 2000.

COSIN-SALES J, CHRISTIANSEN M, KAMINSKI P, OXVIG C, OVERGAARD MT, COLE D, HOLT DW, KASKI JC: Pregnancy-associated plasma protein-A a and its endogenous inhibitor, the proform of eosinophil major basic protein (proMBP), are related to complex stenosis morphology in patients with stable angina pectoris. Circulation 109: 1724-1728, 2004.

COSIN-SALES J, KASKI JC, CHRISTIANSEN M, KAMINSKI P, OXVIG C, OVERGAARD MT, COLE D, HOLT DW: Relationship among pregnancy associated plasma protein-A levels, clinical characteristics, and coronary artery disease extent in patients with chronic stable angina pectoris. Eur Heart J 26: 2093-2098, 2005.

DOMINGUEZ-RODRIGUEZ A, ABREU-GONZALEZ P, GARCIA-GONZALEZ M, FERRER J, VARGAS M: Circulating pregnancy-associated plasma protein A is not an early marker of acute myocardial infarction. Clin Biochem 38: 180-182, 2005.

FARB A, BURKE AP, TANG AL, LIANG TY, MANNAN P, SMIALEK J, VIRMANI R: Coronary plaque erosion without rupture into a lipid core. A frequent cause of coronary thrombosis in sudden coronary death. Circulation 93: 1354-1363, 1996.

GLERUP S, BOLDT HB, OVERGAARD MT, SOTTRUP-JENSEN L, GIUDICE LC, OXVIG C: Proteinase inhibition by proform of eosinophil major basic protein (pro-MBP) is a multistep process of intra- and intermuscular disulfide rearrangements. $J$ Biol Chem 280: 9823-9832, 2005.

HEESCHEN C, DIMMELER S, HAMM CW, FICHTLSCHERER S, SIMOONS ML, ZEIHER AM, CAPTURE Study Investigators: Pregnancy-associated plasma protein-A levels in patients with acute coronary syndromes: comparison with markers of systemic inflammation, platelet activation, and myocardial necrosis. $\mathrm{J} \mathrm{Am} \mathrm{Coll}$ Cardiol 45: 229-237, 2005.

JADLOWIEC J, DONGELL D, SMITH J, CONOVER C, CAMPBELL P: PAPP-A is involved in matrix mineralization of human adult mesenchymal stem cells and angiogenesis in the chick CAM. Endocrinology 146: 3765-3772, 2005.

KALOUSOVÁ M, HOŘEJŠÍ M, FIALOVÁ L, SOUKUPOVÁ J, SULKOVÁ S, MALBOHAN I, TESAŘ I, ZIMA T: Increased levels of pregnancy-associated plasma protein A are associated with mortality in hemodialysis patients: preliminary results. Blood Purif 22: 298-300, 2004.

KHOSRAVI J, DIAMANDI A, KRISHNA RG, BODANI U, MISTRY J, KHAJA N: Pregnancy associated plasma protein-A: ultrasensitive immunoassay and determination in coronary heart disease. Clin Biochem 35: 531-538, 2002.

LATERZA OF, CAMERON SJ, CHAPPELL D, SOKOLL LJ, GREEN GB: Evaluation of pregnancy-associated plasma protein A as a prognostic indicator in acute coronary syndrome patients. Clin Chim Acta 348: 163-169, 2004. 
LAURSEN LS, OVERGAARD MT, SOE R, BOLDT HB, SOTTRUP-JENSEN L, GIUDICE LC, CONOVER CA, OXVIG C: Pregnancy-associated plasma protein-A (PAPP-A) cleaves insulin-like growth factor binding protein (IGFBP)-5 independent of IGF: Implications for the mechanism of IGFBP-4 proteolysis by PAPP-A. FEBS Lett 504: 36-40, 2001.

LAWRENCE JB, OXVIG C, OVERGAARD MT, SOTTRUP-JENSEN L, GLEICH GJ, HAYS LG, YATES JR 3rd, CONOVER CA: The insulin-like growth factor (IGF)-dependent IGF binding protein-4 protease secreted by human fibroblasts is pregnancy-associated plasma protein-A. Proc Natl Acad Sci USA 96: 3149-3153, 1999.

LUND J, QIN Q-P, ILVA T, PETTERSSON K, VOIPIO-PULKKI LM, PORELA P, PULKKI K: Circulating pregnancy-associated plasma protein-A predicts outcome in patients with acute coronary syndrome but no troponin I elevation. Circulation 108: 1924-1926, 2003.

OXVIG C, SAND O, KRISTENSEN T, GLEICH GJ, SOTTRUP-JENSEN L: Circulating human pregnancy-associated plasma protein-A is disulfide-bridged to the proform of eosinophil major basic protein. J Biol Chem 268: 12243-12246, 1993.

OXVIG C, HAANING J, KRISTENSEN L, WAGNER JM, RUBIN I, STIGBRAND T, GLEICH GJ, SOTTRUPJENSEN L: Identification of angiotensinogen and complement C3dg as novel proteins binding the proform of eosinophil major basic protein in human pregnancy serum and plasma. $J$ Biol Chem 270: 13645-13651, 1995.

OVERGAARD MT, OXVIG C, CHRISTIANSEN M, LAWRENCE JB, CONOVER CA, GLEICH GJ, SOTTRUPJENSEN L, HAANING J: Messenger ribonucleic acid levels of pregnancy-associated plasma protein-A and the proform of eosinophil major basic protein: expression in human reproductive and nonreproductive tissues. Biol Reprod 61: 1083-1089, 1999.

OVERGAARD MT, HAANNING J, BOLDT HB, OLSEN IM, LAURSEN LS, CHRISTIANSEN M, GLEICH GJ, SOTTRUP-JENSEN L, CONOVER CA, OXVIG C: Expression of recombinant human pregnancy-associated plasma protein-A and identification of the proform of eosinophil major basic protein as its physiological inhibitor. J Biol Chem 275: 31128-31133, 2000.

QIN Q-P, LAITINEN P, MAJAMAA-VOLTTI K, ERIKSSON S, KUMPULA E-K, PETTERSSON K: Release patterns of pregnancy associated plasma protein A (PAPP-A) in patients with acute coronary syndromes. Scand Cardiovasc J 36: 358-361, 2002.

QIN Q-P, KOKKALA S, LUND J, TAMM N, VOIPIO-PULKKI L-M, PETTERSSON K: Molecular distinction of circulating pregnancy-associated plasma protein A in myocardial infarction and pregnancy. Clin Chem 51: 7583, 2005.

QIN Q-P, KOKKALA S, LUND J, TAMM N, QIN X, LEPANTALO M, PETTERSSON K: Immunoassays developed for pregnancy-associated plasma protein-A (PAPP-A) in pregnancy may not recognize PAPP-A in acute coronary syndromes. Clin Chem 52: 398-404, 2006.

RAUCH AE, AMYOT KM, DUNN HG, NG B, WILNER G: Hypereosinophilic syndrome and myocardial infarction in a 15-year-old. Pediatr Pathol Lab Med 17: 469-486, 1997.

RESCH ZT, CHEN BK, BALE LK, OXVIG C, OVERGAARD MT, CONOVER CA: Pregnancy-associated plasma protein a gene expression as a target of inflammatory cytokines. Endocrinology 145: 1124-1129, 2004.

SLUNGAARD A, VERCELLOTTI GM, TRAN T, GLEICH GJ, KEY NS: Eosinophil cationic granule proteins impair thrombomodulin function. A potential mechanism for thromboembolism in hypereosinophilic heart disease. J Clin Invest 91: 1721-1730, 1993.

SPENCER K: The influence of different sample collection types on the levels of markers used for Down's syndrome screening as measured by the Kryptor immunoassay system. Ann Clin Biochem 40: 166-168, 2003.

ŠTULC T, MALBOHAN I, MALÍK J, FIALOVÁ L, SOUKUPOVÁ J, ČEŠKA R: Increased levels of pregnancyassociated plasma protein-A in patients with hypercholesterolemia: the effect of atorvastatin treatment. Am Heart J 146: 1060-1063, 2003.

SWETS JA: Measuring the accuracy of diagnostic systems. Science 240: 1285-1293, 1988.

TAI PC, ACKERMAN SJ, SPRY CJ, DUNNETTE S, OLSEN EG, GLEICH GJ: Deposits of eosinophil granule proteins in cardiac tissues of patients with eosinophilic endomyocardial disease. Lancet 1: 643-647, 1987. 